ISSUE BRIEF

\title{
Finding a Way from the Margins to the Middle Library Information Technology, Leadership, and Culture
}

May 18, 2017

Dale Askey

McMaster University

Lisa Janicke Hinchliffe

University of Illinois at Urbana-Champaign

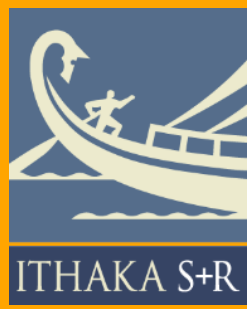




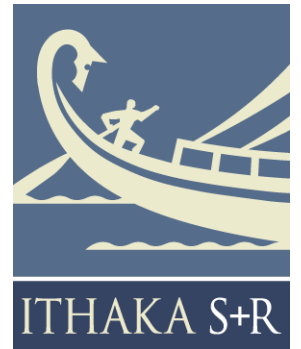

Ithaka $\mathrm{S}+\mathrm{R}$ is a strategic consulting and research service provided by ITHAKA, a not-for-profit organization dedicated to helping the academic community use digital technologies to preserve the scholarly record and to advance research and teaching in sustainable ways. Ithaka $\mathrm{S}+\mathrm{R}$ focuses on the transformation of scholarship and teaching in an online environment, with the goal of identifying the critical issues facing our community and acting as a catalyst for change. JSTOR, a research and learning platform, and Portico, a digital preservation service, are also part of ITHAKA.

Copyright 2017 Dale Askey and Lisa Janicke Hinchliffe. This work is licensed under a Creative Commons AttributionNonCommercial 4.0 International License. To view a copy of the license, please see http://creative-

commons.org/licenses/by-nc/4.0/.

ITHAKA is interested in disseminating this brief as widely as possible. Please contact us with any questions about using the report: research@ithaka.org. 
Given the number and variety of significant information technology projects led or supported by research libraries, one could incorrectly assume that information technology has been successfully integrated into our organizations. Unlike other recent library service program developments-namely, information literacy and scholarly communication, which also started on the margins-information technology has not found its way to the "middle" in most of our organizations. Information technology workers, not solely but in particular, experience a lingering divide between the culture of the information technology unit and the library culture at large as an unproductive chasm. As a result, libraries fail to develop the full potential in their technologydependent service programs and, ultimately, library users are left without the kinds of programs and products that would create real value for them.

As with more and more collaborations these days, this Issue Brief has its origins in an exchange on social media, a short but provocative discussion of Library IT and organizational structure. Ultimately, the authors decided to submit a proposal to speak at CNI, hopeful but frankly skeptical that the topic would resonate with attendees who generally seek out project updates. While we had hoped for perhaps a dozen or two people, approximately 65 attended. Aside from the strong turnout, what surprised but heartened us was how eager the audience was to participate in a discussion. It was also clear that many had come seeking answers to or suggestions for some of the real issues they face in recruiting and retaining staff in information technology roles. While the discussion resulted in few answers, this Issue Brief stands as the next attempt to continue this conversation in pursuit of strategies and tactics to address these challenging issues. ${ }^{1}$

\section{Locating Information Technology within the Library}

Large academic libraries, and perhaps some smaller ones as well, are facing the same challenge as many organizations of engaging with their users online. As Marty Cagan observes in the for-profit sector:

Over the past 10 years, virtually all of these companies as well as those from dozens of other industries have realized that they need to use the Internet to engage directly with their customers online ... many of these companies are trying

\footnotetext{
${ }^{1}$ The description of the CNI session includes a link to our presentation slides. See https://www.cni.org/topics/economicmodels/from-invasive-to-integrated-information-technology-and-library-leadership-structure-and-culture. We also each blogged our reflections. See Dale Askey, "IT Leadership Issues in Libraries," Bibliobrary, April 15, 2016, https://bibliobrary.net/2016/04/15/it-leadership-in-libraries/, and Lisa Janicke Hinchliffe, "Information Technology in Research Libraries \#CNI16S," April 13, 2016, https://isahinchliffe.com/2016/04/13/infotech-in-research-libs/. This Issue Brief draws on these documents but further expands our thinking and the implications of our claims.
} 
to manage this new customer-facing internet software as if it were their internalfacing information technology software, and the result is that many of these companies provide terrible online customer experiences, and worse, they don't have the organization, people or processes in place to improve them. ${ }^{2}$

The same can be said of the non-profit sector and of academic libraries specifically. Existing strategies and structures that developed to manage technology used by staff are ill-suited to and straining under the demands of providing services to the communities served by the library. In addition to failing to meet user needs, tensions and even conflict can develop within libraries and among different staff groups. When an us-vs-them mindset emerges, it erodes morale as well as quality of service.

\section{Existing strategies and structures that developed to manage technology used by staff are ill-suited to and straining under the demands of providing services to the communities served by the library.}

To pursue this conversation about technology culture as something different and separate from library culture and positing that these two cultures often conflict in unproductive ways requires an understanding of what we mean by information technology and how we define library subcultures. Clearly, larger academic libraries in North America use various organizational models. (Our comments here apply to libraries large enough to have a technology culture, so perhaps libraries with 50 employees or more, though it is possible for smaller organizations to also have subcultures and so this is a not a hard delineation.) Yet if one discards some of the outliers, i.e., those few that remain ultra-traditional or that have embraced radical new forms, one can assert relatively safely that most libraries are more alike than different in terms of general organizational structure and dynamics. Specifically, one can confidently predict and expect to find a stand-alone "information technology" unit, typically staffed with no or only a few "librarians" and treated as separate from library services and collections. Though there is some evidence that library administrators are not satisfied with this arrangement, this structure remains unchanged and mostly unchallenged. ${ }^{3}$

2 "Moving from an IT to a Product Organization," Insights Blog, July 6, 2008, http://www.svpg.com/moving-from-an-it-to-aproduct-organization/.

${ }^{3}$ Roger C. Schonfeld, "How Should We Organize the Academic Library? The View from the Director's Chair," Ithaka $S+R$ (blog), August 18, 2016, http://www.sr.ithaka.org/blog/how-should-we-organize-the-academic-library/. 
Though the organizational structure is rather uniform, the technological situation of libraries varies greatly. Some libraries operate their own data centers and have full control over all aspects of technology use in their buildings and online. Others are dependent upon-by choice or by mandate-campus or other external providers for core infrastructure such as storage and servers. Nevertheless, practically all academic libraries maintain control over library-specific software and manage extensive library websites that often require ongoing local development, support, and customization to meet the needs of library users. Given this set of tasks, it is not surprising that most academic libraries have a number of staff on hand that are typically referred to collectively as information technology, however ill-fitting that term may be with regard to the actual work of the individuals. These positions include web managers, user experience specialists, content developers, software developers, and desktop support specialists, as well as database, system, network, and application administrators.

Framed somewhat differently, the information technology cluster in academic libraries typically consists of the people who regularly attend conferences such as Code4Lib (and its regional affiliates), the DLF Forum, Open Repositories, and Access. At those events, there may be a small subset of people from outside of the information technology box on a library's organizational chart, but overall the attendees are fairly homogenous with regard to structural home within their library organizations. We are seeing some demographic shifting in recent years, not least with the resurgence of the DLF Forum as a fruitful meeting ground between those with more technical skill and those from services and collections that want to work collaboratively to develop our future services. Hopefully this trend will continue but at the moment it remains a relatively unique exception.

The portrayal here plays fairly loosely with the term "information technology," sometimes implying that it represents a distinct organizational form, such as a department or a tight cluster on an organizational chart, at others seeming to frame it in terms of culture or skill sets. Often times the structure is as simple as the former, although these departments often have names other than information technology applied to them of course, e.g., digital initiatives, library systems, digital experience, etc. We assert that regardless of formal structure, there exists in most libraries a group of individuals whose work is highly technical and tends to be regarded in toto by most of the organization and certainly by its leadership as the information technology group. An element common to any scenario is that they are typically perceived first as technologists, not as library staff, i.e., not performing the functions we tend to speak of generally as "library" work.

The emergence of new, neither fish nor fowl, centers of activity in our organizationse.g., digital humanities/scholarship, digitization, research data management-that 
require technical understanding closely aligned with subject or other specialized knowledge complicates the picture; however, it also perhaps in some ways reinforces the notion that there is a core and a periphery in our libraries, and that information technology and these newer services are still orbiting on the periphery.

\section{From the Margins to the Middle}

The only ur-function of the library, one could assert, is to hold titles in a collection. It follows from this that one must have a system for finding the items, so libraries of necessity developed methods of cataloging and classification, and then services to assist patrons with them. The point here is not to trace the development of libraries, but merely to illustrate that, while any enterprise has clearly delineated core functions, change comes in the form of new work that arrives on the periphery of the organization. Some of it remains there, has a brief lifespan, and then disappears again (e.g., CD-ROM towers as information platforms). Other work grows in scope, accruing more human resources and establishing its footing, ultimately moving from the periphery to the center where it becomes something "we have always done" and no longer must assert its specific relevance. Within the last two or three decades, we have seen this occur in libraries with regard to their role in information literacy education and scholarly communication advocacy and services. While they may operate under various names in libraries, they are omnipresent. 4

\section{In contrast to information literacy education and scholarly communications services, information technology as a center of work in libraries appears to be stalled somewhere along the transition from the marginal to the central.}

In contrast to information literacy education and scholarly communications services, information technology as a center of work in libraries appears to be stalled somewhere along the transition from the marginal to the central. Clearly, no large library could dispense entirely with an information technology unit or at least with the work performed by information technology staff. Yet, we have yet to see broad acceptance and integration of this work across and through our organizations. Given that most people

\footnotetext{
${ }^{4}$ Matthew P. Long and Roger C. Schonfeld, "Ithaka S+R US Library Survey 2013," Ithaka S+R, March 11, 2014, https://doi.org/10.18665/sr.22787.
} 
currently in library leadership roles do not have a background in information technology, but rather emerged from more established centers of work, this should perhaps not be that surprising; however, the lack of a digital mindset is impeding library success. ${ }^{5}$

The failure to fully embrace and integrate information technology into the larger library organizational culture stems from a number of factors as well as engenders some fairly negative outcomes that one can broadly observe in libraries.

- One of the most obvious problems facing libraries is that it can be exceedingly difficult to recruit and retain leadership positions in libraries. Candidate pools are small and those who already hold such positions are frequently asked to apply for positions that would be lateral career moves.

- Information technology staff and ideas are too often excluded from library strategic planning and initiatives, i.e., they are not engaged in developing the library's agenda and plans, but rather reacting to them, often being brought in at the implementation phase of ideas, rather than in the development phase.

- The silo-ing of information technology into a single unit, on a macro and/or micro scale depending on the library, results in libraries experiencing some of the more negative aspects of the information technology working environment can be seen in the broader information technology industry. Put succinctly, it fosters the continued development and existence of nearly all male units, where information technology work happens in a club-like environment behind a mysterious curtain (or perhaps just a locked door) where women and people of color may be unwelcome or even harassed.

- Last, but hardly least in terms of impact, it means that libraries are stuck in catch up mode relative to larger trends in technological progress. While the information technology staff are often in tune with the broader technology and web environments, key decisions are still made elsewhere in the organization by many who have outdated or partial understanding, at best. In terms of funding decisions, budgets continue to reflect an emphasis on in-building services over digital services, regardless of trends in user behaviors and preferences.

Below we include five observations as to what causes the silo-ing of the information technology function within libraries. We do not assume that these observations are universally valid in all libraries in equal measure, but aver that they do seem to hold sway generally in our profession. They point toward why information technology's progression from the margins to the middle of organizations has been slow in many libraries and in the field overall.

\footnotetext{
${ }^{5}$ Deanna Marcum, "Library Leadership for the Digital Age," Ithaka $S+R$, March 28, 2016, https://doi.org/10.18665/sr.277583.
} 
1. When hiring for information technology leadership positions, libraries emphasize information technology knowledge over library contextual knowledge and experience. Often, information technology leadership job postings demand both a depth and specificity of information technology knowledge that is not required to manage information technology work, but rather to perform it. This disqualifies many people who are working in libraries from moving into information technology mid-career. If one combines this factor with well-documented differences between men and women with regard to self-assessment of expertise and fit for a particular job, ${ }^{6}$ and the fact that the majority of people working in libraries are women, one can begin to understand why these positions go unfilled for lack of applicants or are often filled with men drawn from information technology management ranks or computer science programs, i.e., outsiders, in a sense. These hiring patterns reinforce the perception that the information technology unit is distinct from the library in which it resides.

2. Information technology often lives off to the side of the organizational chart as an administrative appendage. Technical staff are rarely distributed throughout the organization in a way that would put them in closer proximity to the other library functions that their work helps shape and that should shape information technology work. This also exacerbates the stereotype fairly endemic in libraries that all information technology people are interchangeable. Library administrators far too often refer to information technology staff as "information technology guys" or "techies" as if there is a uniformity and fungible quality to technology staff positions. Role differentiation within information technology units, on the other hand, is clear: a programmer is not a system administrator, a desktop support specialist is not a web designer, etc.

3. Library information technology staff are generally blocked from entering library leadership roles except for those within the library information technology silo. While their excellence within the information technology realm may be lauded and rewarded, their lack of work experience in other library functional areas makes libraries wary of granting them broader leadership roles. For libraries that require a master's in library science for professional positions outside of information technology, the degree requirement serves to further isolate library information technology staff.

4. Information technology functions on shorter and more iteratively driven timelines than other library units. Librarians pride themselves on their ability to thrive in a constantly changing information environment. Yet the rate of change in libraries broadly pales in comparison to the rate of change in the broader information technology realm. Given that libraries have zero agency in terms of setting broader

\footnotetext{
${ }^{6}$ Katty Kay and Claire Shipman, "The Confidence Gap," The Atlantic, May 2014, http://www.theatlantic.com/magazine/archive/2014/05/the-confidence-gap/359815/;

Tara Sophia Mohr, "Why Women Don't Apply for Jobs Unless They're 100\% Qualified," Harvard Business Review, August 25, 2014, https://hbr.org/2014/08/why-women-dont-apply-for-jobs-unless-theyre-100-qualified.
} 
societal information technology agendas and trends, it is imperative that library information technology functions be nimble and responsive to minute changes or risk being left behind using technology that vendors have abandoned. This pace of work is difficult to mesh with general timeframes and workflows in libraries.

5. Information technology units are perceived as overly rigid and dismissive of others' ideas, although the actions that lead to this perception are often born of selfpreservation necessity. Few libraries are blessed with excessive or generous staffing numbers, but the aforementioned failure to recognize proper information technology role differentiation means that information technology staff-already working in minimally staffed environments-are generally hit from all sides by a wide array of generic requests for assistance, whether they are actually in scope for the position that the library has hired them to do. Too many times a library's system administrator is also performing end-user support, developing extensive custom software, helping with desktop support issues, and so forth. In this environment, it should not be surprising that when the library comes along with a great idea that "just" needs "someone in information technology" to realize, the information technology staff may not respond enthusiastically.

As noted, not all five of the assertions will play out in equal measure as described here in all libraries. We do suggest, however, that within these assertions lie the core dynamics of the library's relationship to information technology work performed within the organization, and that they contribute significantly to organizational dysfunction and generate disruptive strife and conflict. Aside from damaging effects on workplace morale and retention struggles, these conflicts result in missed opportunities for libraries.

\section{Libraries squander a great deal of talent by not recognizing the career aspirations of people in information technology}

roles.

Many of the negative impacts are felt within the information technology areas within the library. Talented staff find that they must leave the organization in order to grow their careers and find the work they want to do. If they are librarians working in information technology, they have likely found that they cannot advance within their own organizations, so look elsewhere for that step up. If they are deeply skilled programmers or system administrators-whether librarians or not-they can frequently find better paying work outside libraries that does not require them to be all-purpose information technology problem solvers. Libraries squander a great deal of talent by not recognizing the career aspirations of people in information technology roles. 
Given the interplay of how we describe, hire, and promote information technology work in libraries, it should not surprise us that our information technology staff are often the library turned on its head in terms of gender ratios. While the broader library may be 7080\% women, the information technology shop typically skews the other way, perhaps cementing a cultural conflict in place. The negative work dynamic within many tech shops has been widely exposed in recent years by high profile cases of sexual harassment in the gaming industry and in startups such as Uber, as well as through books such as Elissa Shevinsky's Lean Out: The Struggle for Gender Equality in Tech and Start-up Culture. While the toxicity one sees in startups and major tech firms does not typically exist within libraries, we would be naive to assume that our organizations are immune from or do not participate in these broader phenomena. The culture that tends to emerge in information technology clusters, even in libraries and regardless of how well humored it may be, repels people (women and men alike) who do not want to participate in objectionable and destructive cultures.

\section{Our users want and expect our services to operate in a manner akin to the rest of their digital lives, and it is plainly clear that we are not meeting that challenge.}

Given the centrality of technology to nearly every facet of modern library work, we cannot continue to tolerate such a culture gap. Our users want and expect our services to operate in a manner akin to the rest of their digital lives, and it is plainly clear that we are not meeting that challenge. That libraries are losing out to other providers is well known and understood, but perhaps only with regard to discovery and Google's displacement of libraries as the discovery environment of choice. The next great challenge we are facing is with content delivery. Most of us use an antiquated technology-EZproxy-to enable our users to access licensed content from offsite. SciHub, despite its egregious abuse of copyright, has made major inroads with faculty in particular for the simple reason that it is dead easy to use: zero-barrier access to scholarship from anywhere, anytime. We need something more than strongly worded statements to compete in this environment, yet we continue to twiddle our thumbs, technologically speaking. Given the opportunities presented by modern technologies, from linked open data to Elasticsearch, we should be aggressively pursuing new areas of influence and impact, 7 but too often our information technology staff are still tethered-

\footnotetext{
${ }^{7}$ Mita Williams makes this case strongly in "Why Libraries Should Maintain the Open Data of Their Communities," Librarian of Things (blog), November 11, 2016, https://librarian.aedileworks.com/2016/11/11/why-libraries-shouldmaintain-the-open-data-of-their-communities/.
} 
by organizational demands into which they have minimal input due to their marginal position-to antiquated technologies that require constant care and attention.

\section{Moving Information Technology to the Middle}

So, what is to be done? We have observed in this Issue Brief that information literacy education and scholarly communications services are two areas that have moved from the "margins to the middle" in academic libraries recently and have argued that the siloing of information technology has resulted in its staying at the organizational periphery.

Reflection upon the movement of information literacy and scholarly communication to the core reveals some possible strategies for thinking about the organizational integration of information technology in libraries. Information literacy was a contested area of work as recently as the early 1990 s when library leaders questioned whether librarians should be educators. Scholarly communications is a more recently developed service area and, though the parameters are still being defined, it is already codified in library strategic plans and a rapidly developing specialty staffed by professionals with a great variety of educational backgrounds.

\section{Library leaders need to have a vision of and commitment to library information technology as a strategic asset and not only an operational utility.}

Three factors appear key in transforming information literacy and scholarly communications from operational activities into strategic initiatives: leadership, structure, and culture. For each of these, there are possible lessons for strategically approaching information technology:

- Leadership - Library administrators communicate a vision for information literacy and scholarly communications as important and necessary areas of library development to meet institutional needs. Library leaders need to have a vision of and commitment to library information technology as a strategic asset and not only an operational utility. When hiring library information technology leaders, search committees should look for candidates from within traditional information technology units but also consider individuals who have leveraged technology in services or collections work. They should learn to differentiate the management of information technology from the performance of information 
technology work; in plain text, one need not have advanced programming or system admin skills to manage technology projects and staff.

- Structure - Information literacy and scholarly communications are typically articulated as a collective responsibility, even when there is a central leader/coordinator and unit, with a large percentage of the library staff across the organization contributing in some way to the efforts, regardless of reporting line. More traditional collection development work also reflects this model-a central leader with some reporting lines also coordinating across organizational structures. In contrast, library information technology is typically treated as a monolithic unit within an organizational chart, with little attention to role differentiation of the staff, alignment with user services or library collections, or coordination of work of staff in other reporting lines. Having a complementary overlay or matrix structure for how different information technology professionals work collaboratively with other units could highlight the variety of roles within information technology and how they interact with the variety of professionals elsewhere in the organization. There are myriad benefits to approaching information technology as being distributed throughout the organization using such models, perhaps the most obvious being that it thwarts the formation of the all-male IT cluster that displays some of the negative traits endemic to such work environments. For the IT staff, it puts them in closer proximity to other work in the library, which enables their expertise to help set the library's agenda at a much earlier stage in its development than is typically the case with an isolated and virtually external IT appendage.

- Culture - Information literacy and scholarly communications are understood as intimately connected to the ur-function of the library discussed above. In contrast, information technology is often categorized with business and human resources, operationally important but not connected with the library's core mission. When the culture of library information technology is distinct from (and perhaps even in opposition to) the library culture at large, it is a signal that library information technology professionals are, at best, silo-ed in the organization and, potentially worst, alienated and disaffected. Connecting library information technology work to the library's unique mission is crucial to building a shared culture across the organization that values information technology work.

The theme throughout all of these suggestions is intentionality. Library leaders will have to take intentional steps to evolve and change library structure, organization, and culture to capitalize on the promise of information technology to transform our work and better serve our communities of users. 